\title{
Impact of Pore Architecture on the Hydroconversion of Long Chain Alkanes over Micro and Mesoporous Catalysts
}

\author{
Laura Vaugon ${ }^{a}$, Annie Finiels ${ }^{a}$, Thomas Cacciaguerra ${ }^{a}$, Vasile Hulea $^{a}$, Anne Galarneau ${ }^{a}$, Cindy Aquino ${ }^{b}$, \\ Jean-Pierre Dath ${ }^{b}$, Delphine Minoux ${ }^{b}$, Corine Gerardin ${ }^{a}$, and François Fajula ${ }^{a, ~ * ~}$ \\ ${ }^{a}$ Institut Charles Gerhardt, Univ. Montpellier, CNRS, ENSCM, Montpellier, 34095 France \\ ${ }^{b}$ Total Research and Technology Feluy, Feluy, 7181 Belgium \\ *e-mail:ffajula@enscm.fr \\ Received November 15, 2019; revised December 9, 2019; accepted December 10, 2019
}

\begin{abstract}
Hexadecane hydroconversion has been investigated in a series of bifunctionnal metal/acid catalysts featuring distinct well-defined pore architectures. The acidic components were prepared from dealuminated $\mathrm{Y}$ zeolites with $\mathrm{Si} / \mathrm{Al}$ of 15 and 30 post treated in alkaline medium to generate ordered or non-ordered secondary networks of mesopores and from aluminated ordered mesoporous materials MCM-41, MCM-48, KIT-6 type materials and amorphous silica gel. Activity relates linearly to the strength and number of strong Brönsted acid sites, while selectivity, more precisely the yield in isomerization products, scales directly with the mesopore volume of the catalyst. The architecture of the mesoporous network, namely the ordering, interconnectivity, homogeneity of the mesopores, affects little catalytst behavior. Confrontation of catalytic data with diffusion measurements suggests the existence of an optimal mesopore size above which the number of strong Brönsted sites and the mesopore volume are the only parameters governing catalytic performance.
\end{abstract}

Keywords: hydroisomerization, $n$-hexadecane, mesoporous zeolites, MCM-41, MCM-48, KIT-6, diffusion DOI: $10.1134 /$ S0965544120040180

\section{INTRODUCTION}

Hydroconversion (HDC) processes such as hydrocracking and hydroisomerization play a key role in modern refineries as they allow the transformation of a wide range of feed stocks into high value products [1]. Hydroconversion catalysts combine two functions, an acidic component consisting, on the one hand, of an amorphous or crystalline oxide and, on the other hand, of a hydrogenation-dehydrogenation component which formulation depends on the nature and composition of the feed to be converted and the experimental conditions. Under ideal hydroconversion conditions, when the hydrogenating/dehydrogenating function is not limiting, it has been demonstrated for long that product selectivity is strongly impacted by the porosity of the catalysts [2] while it hardly depends on acidity [3]. This can be easily understood since selective hydroconversion processes, which involve multi-site and multi-step catalytic cycles, require fast hydrogenation and desorption of highly reactive olefinic intermediates to prevent consecutive secondary non-selective reactions.

The influence of pore architecture on product selectivity during hydrocracking, where the production of high value middle distillates is targeted, is well illustrated in several papers [4-7]. For instance, in the case of the conversion of a model phenantrene mole- cule over zeolitic catalysts, at a given temperature and total conversion, the yield of the most valuable intermediate hydrocracked products scales almost linearly with the pore size, or the pore volume, of the catalyst [6]. The results were rationalized using a very simple model based on the confinement theory introduced by Derouane et al. [8-10].

In the processing of a real feedstock, consisting in a mixture of straight run VGO, aromatic extract and heavy coker gas oil, over a composite $\mathrm{NiMo} / \mathrm{Al}_{2} \mathrm{O}_{3} /$ Faujasite catalyst, it was shown that the selectivity in middle distillate increased with the mesopore volume generated by a dissolution/reconstruction treatment of the acidic faujasite [7]. In terms of productivity, however, optimal middle distillate yields were obtained with the catalysts where the zeolite component has been only moderately modified which feature the highest acidity.

Hydroisomerization of long chain alkanes is also a domain of strong academic and industrial concern as this reaction is at the basis of very important conversion technologies aiming at improving the cetane number of diesel and jet-fuels and the cold flow properties of fuels and lubricants. The domain has been periodically reviewed [11-16]. Most efforts have been paid to develop catalytic systems and experimental conditions aiming at optimizing the yields of isomers 
while reducing secondary cracking reactions. In that respect a large body of literature has been produced to delineate the ideal characteristics for crystalline and amorphous acidic hydroisomerization catalyst components. It turns out that, when the acidic and metallic functions are well balanced, aside the structural type [17-22], the crystal size and morphology [23, 24] and the nature of the acid sites [25-27] of the zeolite component, the textural features, namely the presence of a secondary network of mesopores, dramatically impacts the isomer selectivity [28-32]. In all cases, selectivity improvement has been related to mass transport enhancement, favoring desorption of the primary isomer products.

In order to better apprehend, and possibly quantify, the beneficial effect of the presence of mesopores on the hydroisomerization selectivity of HDC catalysts, we prepared a series of model catalysts featuring unique and well-defined textural features and pore architectures. The materials have been characterized and their catalytic behavior compared under the very same experimental conditions in the transformation of $n$-hexadecane.

\section{EXPERIMENTAL}

\section{Materials}

Zeolite materials. Zeolite-based catalysts were produced starting from two parent materials obtained from Zeolyst International, namely CBV 720 (FAU type, $\mathrm{Si} / \mathrm{Al}=15$, hereafter HY-15) and CBV 760 (FAU type, $\mathrm{Si} / \mathrm{Al}=28.4$, hereafter $\mathrm{HY}-30$ ). Both materials have been prepared by the supplier by steam dealumination and acid leaching of a parent aluminium-rich faujasite. The pore architecture of the two parent samples has been modified by using various treatments in alkaline medium in order to increase and re-engineer their secondary mesoporous network.

HY-30 meso-d was obtained by submitting the parent HY-30 to a desilication treatment with $0.05 \mathrm{M}$ $\mathrm{NaOH}$ solution at room temperature for $15 \mathrm{~min}$ as described in ref [28].

HY-15 meso-r and HY-30 meso-r were produced by a desilication/reconstruction protocol in the presence of cetyltrimetylammonium bromide (CTAB) surfactant [32-39] by reaction for $20 \mathrm{~h}$ at $150^{\circ} \mathrm{C}$ with a $0.09 \mathrm{M}$ solution of tetramethyl ammonium hydroxide (TMAOH) for HY- 15 meso-r, and for $1 \mathrm{~h}$ at $150^{\circ} \mathrm{C}$ with a $0.07 \mathrm{M}$ solution of TMAOH for HY-30 meso-r [40, 41].

The as-synthezized materials were oven dried overnight at $80^{\circ} \mathrm{C}$ and finally calcined at $550^{\circ} \mathrm{C}$ for $8 \mathrm{~h}$ under air flow. The material HY-30 meso-d is obtained as $\mathrm{Na}^{+}$form and requires a cation-exchange (see below) to provide $\mathrm{H}^{+}$form. HY-15 meso-r and HY-30 meso-r are directly produced under $\mathrm{H}^{+}$form.
Mesosporous materials. LiChrospher 60 has been given by Merck and consists in $12 \mu \mathrm{m}$ silica-gel particles with a mesopore network with pore openings centered at $6 \mathrm{~nm}$.

A large-pore silica material with cubic $\mathrm{I}_{\mathrm{a} 3 \mathrm{~d}}$ symmetry, named KIT-6 [42] was synthesized by reaction in teflon-lined autoclave at $130^{\circ} \mathrm{C}$ for $24 \mathrm{~h}$ of a mixture of triblock-copolymer Pluronic P123 $\left(\mathrm{EO}_{20} \mathrm{PO}_{70} \mathrm{EO}_{20}\right.$, Aldrich) and butanol as structuring agents, tetraethylorthosilicate (TEOS) as silicon source and $\mathrm{HCl}$, after an aging of $24 \mathrm{~h}$ at $35^{\circ} \mathrm{C}$ [43]. The molar composition of the starting gel was: $1 \mathrm{SiO}_{2} / 0.017 \mathrm{P} 123 / 1.9 \mathrm{HCl} / 1.3$ butanol/194 $\mathrm{H}_{2} \mathrm{O}$. The slurry was then filtered and washed rapidly with a $\mathrm{HCl} / \mathrm{EtOH}$ solution before to be dried at $100^{\circ} \mathrm{C}$ for $24 \mathrm{~h}$ and calcined at $550^{\circ} \mathrm{C}$ for $8 \mathrm{~h}$.

The MCM-41 sample (Al-MCM-41, Si/Al = 15) was synthesized using Aerosil 200 as silica source, CTAB as surfactant, $\mathrm{NaOH}$, deionized water in molar composition: $1 \mathrm{SiO}_{2} / 0.1 \mathrm{CTAB} / 0.25 \mathrm{NaOH} / 0.066$ $\mathrm{NaAlO}_{2} / 20 \mathrm{H}_{2} \mathrm{O}[44,45]$. After dissolution of CTAB in water in presence of $\mathrm{NaOH}$ and $\mathrm{NaAlO}_{2}$ at $50^{\circ} \mathrm{C}$, silica is added progressively and the suspension is stirred for $1 \mathrm{~h}$. The slurry is then put in autoclave for $20 \mathrm{~h}$ in static condition at $115^{\circ} \mathrm{C}$. The resulting slurry is then filtered and washed with water until neutral $\mathrm{pH}$, dried at $80^{\circ} \mathrm{C}$ overnight and calcined at $550^{\circ} \mathrm{C}$ for $8 \mathrm{~h}$.

Silica MCM-48 was synthesized by following the procedure recommended by Galarneau et al. [46] from powdered silica (Aerosil 200), CTAB, $\mathrm{NaOH}$ and deionized water in the following molar composition: $1 \mathrm{SiO}_{2} / 0.38 \mathrm{NaOH} / 0.175 \mathrm{CTAB} / 120 \mathrm{H}_{2} \mathrm{O}$. After dissolution of CTAB in water in the presence of $\mathrm{NaOH}$ at $50^{\circ} \mathrm{C}$, silica was added progressively and the suspension was stirred for $2 \mathrm{~h}$. The slurry was then put in autoclave at $150^{\circ} \mathrm{C}$ for $15 \mathrm{~h}$ without stirring. The solid precipitate was then filtered, not washed, and dried at $80^{\circ} \mathrm{C}$ overnight. The resulting powder was then subjected to two successive hydrothermal post-treatments in deionised water at $130^{\circ} \mathrm{C}$ for $6 \mathrm{~h}$. Between each post-treatment, the suspension was filtered, not washed, and dried at $80^{\circ} \mathrm{C}$ overnight. After the second post-treatment, the slurry was filtered and washed until neutral $\mathrm{pH}$ before being dried at $80^{\circ} \mathrm{C}$ overnight and calcined at $550^{\circ} \mathrm{C}$ for $8 \mathrm{~h}$. This procedure is important in order to improve the thermal, chemical and mechanical stabilities of MCM-48 [46].

Alumination of the surface of the mesoporous silica materials. In order to generate acid sites, aluminium species were grafted at the surface of the siliceous mesoporous silica materials MCM-48, KIT-6 and LiChrospher according to two procedures.

MCM-48 was aluminated according to a method similar to that proposed by Lengo et al. [31, 47] using $\mathrm{Al}\left(\mathrm{O}-\mathrm{sec}-\mathrm{C}_{4} \mathrm{H}_{9}\right)_{3}$ as $\mathrm{Al}$ source. The suspension of MCM-48 in $150 \mathrm{~mL}$ of dry toluene $\left(\mathrm{H}_{2} \mathrm{O}<0.002 \%\right)$ was contacted with triethylamine and $\mathrm{Al}(\mathrm{O}-\mathrm{sec}$ - 
Table 1. Characteristics of the different catalysts

\begin{tabular}{c|l|c|c|c|c|c|c|c|c}
\hline Sample no. & \multicolumn{1}{|c|}{ Catalyst } & $\begin{array}{c}\mathrm{Si} / \mathrm{Al}, \\
\mathrm{mol}\end{array}$ & $\begin{array}{c}\mathrm{Pt}, \\
\mathrm{wt} \%\end{array}$ & $\begin{array}{c}\mathrm{V}_{\text {Total, }} \mathrm{mL} / \mathrm{g} \\
\mathrm{mL} / \mathrm{g}\end{array}$ & $\begin{array}{c}\mathrm{V}_{\text {micro, }} \\
\mathrm{mL}\end{array}$ & $\begin{array}{c}\mathrm{V}_{\text {meso, }} \\
\mathrm{mL} / \mathrm{g}\end{array}$ & $\begin{array}{c}\mathrm{D}_{\text {meso, }}, \\
\mathrm{nm}\end{array}$ & $\begin{array}{c}\text { Acidity, } \\
\mathrm{mmol} / \mathrm{g}\end{array}$ & $\begin{array}{c}\text { Iso } \mathrm{C}_{16} \\
\text { yield } \\
\text { wt \% }\end{array}$ \\
\hline 1 & HY-15 & 15 & 0.5 & 0.43 & 0.37 & 0.06 & $5-50$ & 0.33 & 29.4 \\
3 & HY-15 meso-r & 13 & 0.43 & 0.59 & 0.24 & 0.35 & $3.3 / 5-50$ & 0.27 & 49.3 \\
4 & HY-30 & 28.4 & 0.40 & 0.50 & 0.23 & 0.27 & $5-50$ & 0.23 & 45 \\
5 & HY-30 & 28.4 & 2 & 0.50 & 0.23 & 0.27 & $5-50$ & 0.22 & 46.1 \\
6 & HY-30 meso-d & 23 & 0.5 & 0.52 & 0.15 & 0.37 & $3.3 / 5-50$ & 0.18 & 58 \\
7 & HY-30 meso-r & 22 & 0.46 & 0.58 & 0.24 & 0.35 & 3.9 & 0.18 & 55 \\
$8^{3}$ & MCM-41 & 5 & 0.5 & 0.65 & - & 0.65 & 3.5 & 0.09 & 71.1 \\
9 & LCM-48 & 5 & 0.39 & 0.54 & - & 0.54 & 3.3 & 0.22 & 70.1 \\
10 & KIChrospher & 5 & 0.45 & 0.46 & - & 0.46 & $5-10$ & 0.10 & 66 \\
\hline
\end{tabular}

${ }^{1,2} \mathrm{HY}-30$ has been loaded with 2 different amounts of Pt, ${ }^{3}$ from ref [31], ${ }^{4}$ maximum isomerization C16 yield.

$\left.\mathrm{C}_{4} \mathrm{H}_{9}\right)_{3}$ at $85^{\circ} \mathrm{C}$ for $6 \mathrm{~h}$. The solid recovered by filtration was washed with toluene and then suspended in ethanol containing the stoichiometric amount of water corresponding to the amount needed for a complete hydrolysis of the AlOR groups. The suspension was stirred for $24 \mathrm{~h}$ at $25^{\circ} \mathrm{C}$. The final solid was washed with ethanol, oven dried and calcined in flowing air at $400^{\circ} \mathrm{C}$ for $2 \mathrm{~h}$ and $550^{\circ} \mathrm{C}$ for $4 \mathrm{~h}$.

Surface alumination of KIT- 6 and LiChrospher was achieved according to the procedure described by Luan et al. [48, 49]. The silica materials were suspended under stirring in an aqueous solution containing sodium aluminate (corresponding to a molar ratio $\mathrm{Si} / \mathrm{Al}=5$ ) for $15 \mathrm{~h}$, at room temperature. The solid sample was recovered by filtration, washed with water, dried at $80^{\circ} \mathrm{C}$ in air and calcined for $6 \mathrm{~h}$ in air at $550^{\circ} \mathrm{C}$.

The aluminated mesoporous materials KIT- 6 and LiChrospher, MCM-41 and desilicated zeolite HY-30 meso-d were subjected to a cation-exchange treatment. $6.3 \mathrm{~g}$ of materials were poured in $630 \mathrm{~mL}$ of ethanol solution containing $\mathrm{NH}_{4} \mathrm{NO}_{3}(0.1 \mathrm{M})$. The suspension was maintained under reflux for $1 \mathrm{~h}$, before being filtered without washing. The post-treatment was repeated 3 times. After the third post-treatment the powder was washed with $200 \mathrm{~mL}$ ethanol 3 times, dried at $80^{\circ} \mathrm{C}$ overnight and then calcined at $450^{\circ} \mathrm{C}$ for $6 \mathrm{~h}$.

Catalysts preparation. Bifunctional catalysts were prepared by loading 0.3 to 2 wt $\%$ platinum (Table 1 ) on the acidic supports by using the incipient wetness method at room temperature with hexachloroplatinic acid hexahydrate as metal source $[28,31]$. The solids were oven dried at $80^{\circ} \mathrm{C}$ for $2 \mathrm{~h}$, then at $120^{\circ} \mathrm{C}$ for $12 \mathrm{~h}$ and finally calcined (ramp of $2^{\circ} \mathrm{C} / \mathrm{min}$ ) at $550^{\circ} \mathrm{C}$ in flowing air for $8 \mathrm{~h}$. The catalysts were shaped into $250-425 \mu \mathrm{m}$ particles obtained by compressing the powder under two tons, crushing and sieving.

\section{Methods}

Physicochemical characterization. X-ray diffraction (XRD) patterns were collected using a Bruker D8 Advance diffractometer with a Bragg-Brentano geometry, equipped with a Bruker Lynx Eye detector and using $\mathrm{Cu} K_{\alpha}$ radiation and a $\mathrm{Ni}$ filter. XRD patterns were recorded in the range $4^{\circ}-50^{\circ}(2 \theta)$ to identify zeolite peaks and in the range $0.4^{\circ}-6^{\circ}$ to characterize mesostructure architecture. Textural properties of the materials were determined from $\mathrm{N}_{2}$ adsorptiondesorption isotherms at $77 \mathrm{~K}$ recorded on Micromeritics ASAP 2010 apparatus. The Broekhoff and De Boer (BdB) method was applied to the $\mathrm{N}_{2}$ desorption isotherm to calculate mesopore diameters, as previously recommended for MCM-41 materials [50]. Micropore volumes were evaluated by the corrected tplot method drawn in the domain $0.005<p / p_{0}<0.18$ [51]. Total pore volumes were calculated from the amount of nitrogen adsorbed at a relative pressure $p / p_{0}$ of 0.95 for zeolites and desilicated zeolites and at the end of the mesopore filling for mesoporous materials and transformed zeolites using surfactants.

Transmission electron microscopy (TEM) images were recorded using a JEOL 1200 EX2 microscope operating at $100 \mathrm{kV}$. SEM images and EDX elemental analyses were performed using a FET Quanta 200F microscope operated at $15 \mathrm{kV}$.

The amount of strong acid sites was determined by temperature-programmed desorption of ammonia ( $\mathrm{NH}_{3}$-TPD) using an AUTOCHEM 2910 apparatus from Micromeretics [31]. The samples were pretreated at $550^{\circ} \mathrm{C}$ under airflow $(30 \mathrm{~mL} / \mathrm{min})$ for $10 \mathrm{~min}$. After cooling down to $100^{\circ} \mathrm{C}$, the surface was saturated with ammonia $(45 \mathrm{~mL} / \mathrm{min})$ using a mixture $\mathrm{NH}_{3} / \mathrm{He}(5 \%$ $\mathrm{NH}_{3}$ ) for 30 min. Physisorbed $\mathrm{NH}_{3}$ was removed by evacuation at $120^{\circ} \mathrm{C}$ for $30 \mathrm{~min}$ in a dry helium stream 
(25 mL/min). The ammonia desorption was carried out in a helium stream $(25 \mathrm{~mL} / \mathrm{min})$ at a heating rate of $10^{\circ} \mathrm{C} / \mathrm{min}$ up to $600^{\circ} \mathrm{C}$. The amount of desorbed ammonia was monitored with a thermal conductivity detector. Under these conditions ammonia desorbs in two steps: a low temperature desorption step (with a peak maximum at around $200^{\circ} \mathrm{C}$ ) and a high temperature desorption step with a maximum desorption temperature at around $400^{\circ} \mathrm{C}$. In the following the amount of strong acid sites has been calculated from the area of the high temperature desorption peak. The nature of the acid sites has been monitored by studying the interactions of the surface with perdeuterated acetonitrile by infrared spectroscopy using a Bruker Equinox 55 spectrometer in the transmission mode on selfsupporting wafers. The samples $(20-40 \mathrm{mg})$ were activated under vacuum at $450^{\circ} \mathrm{C}$ for $12 \mathrm{~h}$, and acetonitrile (1.5 Torr) was adsorbed at room temperature. Spectra were recorded after evacuation at increasing temperatures, up to $100^{\circ} \mathrm{C}$.

Catalytic testing. Hydroconversion of $n$-hexadecane (n- $\mathrm{C}_{16}, 99.9 \%$ purity, Sigma Aldrich) was studied in a downstream fixed-bed continuous flow reactor (6 mm ID) using 1-1.3 g of catalyst shaped into 250 $425 \mu \mathrm{m}$ particles $[28,31]$. The catalyst pre-calcined at $550^{\circ} \mathrm{C}$ in flowing air (see above) was reduced in situ in flowing hydrogen $(3 \mathrm{NL} / \mathrm{h})$ at $400^{\circ} \mathrm{C}$ for $12 \mathrm{~h}$ (heating rate $\left.10^{\circ} \mathrm{C} / \mathrm{min}\right)$. The hydrocarbon was pumped at a rate allowing a weight hourly space velocity (WHSV) comprised between 1 and $3 \mathrm{~h}^{-1}$ into a vaporization chamber preheated at $130^{\circ} \mathrm{C}$ and mixed with hydrogen with a molar $\mathrm{H}_{2}$ /hydrocarbon ratio of 4 at a total pressure of $20 \mathrm{~atm}$. The reaction temperature was varied between 220 and $320^{\circ} \mathrm{C}$. After catalyst testing, the reactor was depressurized under hydrogen flow at $300^{\circ} \mathrm{C}$. After $3 \mathrm{~h}$ the flow was switched to nitrogen and the temperature decreased to room temperature.

Reaction products were analyzed by gas chromatography using a fast-GC Agilent $7890 \mathrm{~A}$ chromatograph operated with a GC OpenLAB software. An apolar column was used (100\% dimethylpolysiloxane, $20 \mathrm{~m} \times 100 \mu \mathrm{m} \times 0.4 \mu \mathrm{m}$, Agilent 127-0123). Detection of the products was achieved by FID.

Light hydrocarbons, up to $\mathrm{C}_{9}$, were analyzed on line while the liquid fractions were collected and analyzed separately. The total conversion was defined as $\left(1-F_{\text {hc out }} / F_{\text {hc in }}\right) \times 100$, where $F_{\text {hc }}$ is the molar n- $\mathrm{C}_{16}$ hydrocarbon flow. Product yields are reported on a carbon, or weight, basis. Hydroisomerization products were grouped into three lumps (mono, di and tri branched). Hydrocracking products were grouped by carbon number. In all runs, carbon balances higher than $98 \%$ were achieved.

\section{RESULTS AND DISCUSSION}

\section{Materials}

Texture. Nitrogen adsorption isotherms and characteristic TEM images of the catalysts are presented in Figs. 1-4. The starting materials, HY-15 and HY-30 feature the isotherm shape typical for steam dealuminated zeolites characterized by a flat hysteresis loop in the high pressure range. Such a hysteresis is indicative of the presence of mesopores with a broad distribution of sizes in the range from 5 to higher than $50 \mathrm{~nm}$. The mesopores are distributed over the whole crystal (Fig. 3). The sharp closure of the hysteresis loop at a relative pressure $p / p_{0}=0.43$ is characteristic of cavitation phenomenon and suggests the presence of cavities entrapped in the microporous zeolitic network [52]. After the alkaline treatments HY-30 meso-d, HY-30 meso-r, HY-15 meso-r (samples 2, 5, 6, Table 1), the micropore volume of the samples decreased while their mesopore volume increased to a larger extent as a result of the desilication reaction, evidenced by the increase of the $\mathrm{Si} / \mathrm{Al}$ ratios. The architecture of the new mesopores thus created significantly differs depending on the conditions of the alkaline treatment. The mechanism and the outcome of the desilication of HY-30 by dilute soda in the absence of surfactant (HY-30 meso-d) have been investigated using combined TEM and electron tomography and described in detail in ref [28]. Base leached crystals contain unaffected microporous domains, as in the starting zeolite, while the density and the size of the mesopores have been slightly increased. Remarkably, the alkaline dissolution generated a new network of small mesopores, with a diameter in the range $2-10 \mathrm{~nm}$, interconnected to the larger mesopores or to the surface of the crystals. HY-30 meso-d features therefore a trimodal porosity, with the structural micropores and two distinct networks of mesopores, 2-10 and 5-50 nm, both with non uniform distributions of sizes.

The mesopore architecture of HY-15 meso-r and HY-30-meso-r was somewhat different since the presence of CTAB surfactant in the reaction medium and the experimental conditions allowed the reconstruction of the dissolved matter into ordered silicoaluminate mesoporous structures intimately embedded in the zeolite crystal $[39-41,52,53]$. The presence of mesopores with a narrow distribution of sizes at $3.9 \mathrm{~nm}$ is evidenced from the sorption isotherm by the adsorption step at $p / p_{0}=0.37$. The isotherm also reveals that crystal reconstruction has resulted in the disappearance of the large mesopores of 5-50 nm present in the starting material. In the TEM images, we can see that these ordered mesopores are distributed over the whole crystal together with nanodomains of a few hundreds of $\mathrm{nm}$ of crystalline zeolite. HY-15 meso-r and HY-30-meso-r can be therefore regarded as composite materials with hierarchical porosity, consisting of zeolitic and mesostructured 


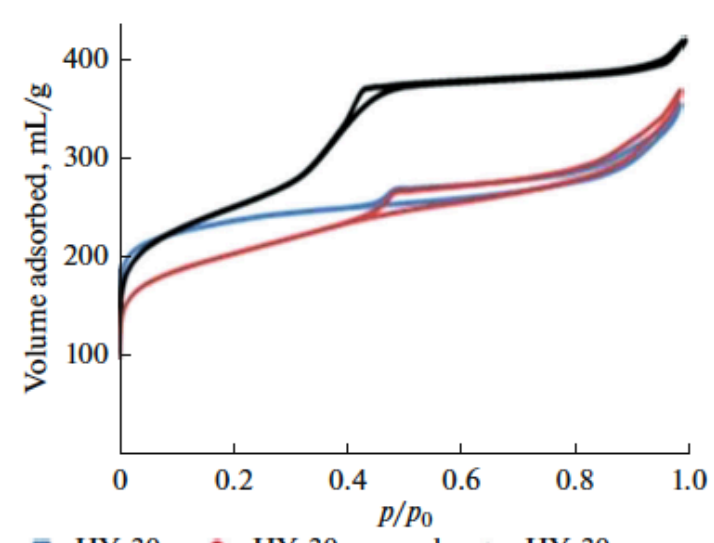

HY-30 $\rightarrow$ HY-30 meso-d $\multimap$ HY-30 meso-r

Fig. 1. Nitrogen sorption isotherms at $77 \mathrm{~K}$ of materials derived from HY- 30 .

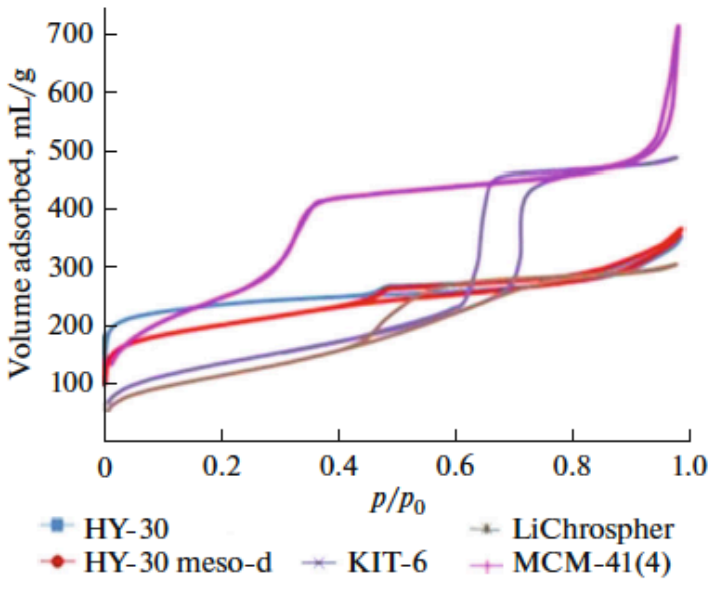

Fig. 2. Nitrogen sorption isotherms at $77 \mathrm{~K}$ of zeolitic and mesoporous materials.
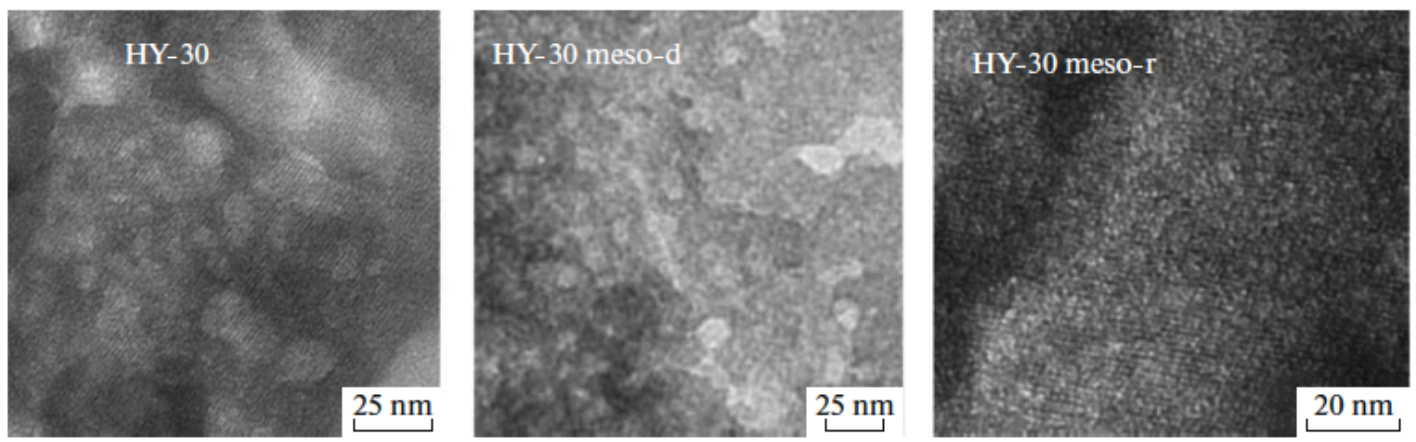

Fig. 3. TEM images of zeolitic materials.

nanodomains as reported for the first time by Goto et al. [33] and further by others [40, 53-56].

The pore architecture of the purely mesoporous materials was more straightforward. MCM-48 and KIT-6 feature a cubic Ia3d symmetry with a bicontinuous gyroid mesostructure. Their pores are $3 \mathrm{D}$ interconnected with a very narrow distribution of sizes (Fig. 4) centered at 3.7 and $7.2 \mathrm{~nm}$ for MCM-48 [31] and KIT-6, respectively, derived from the position of the steep adsorption step of the isotherms. TEM images (Fig. 4) reveal moreover that the pores are very well ordered over the whole particles. After alumination by aluminium alkoxide, MCM-48 features a slight decrease in mesopore diameter of $3.5 \mathrm{~nm}$.

MCM-41 exhibits an ordered one directional (1 D) system of pores in line with the hexagonal P6mm symmetry of the mesophase with uniform pore diameters of $3.5 \mathrm{~nm}$. Similar to the cubic systems, TEM reveals the presence of pores in all the volume of the particles (Fig. 4).
LiChrospher is produced by the aggregation of $12 \mathrm{~nm}$ silica-gel particles (Fig. 4) producing a 3D network of interconnected mesopores with a distribution of sizes $(5-10 \mathrm{~nm})$ centered at $6 \mathrm{~nm}$ (cavities around $6.5 \mathrm{~nm}$ and constrictions around $4.5 \mathrm{~nm}$ diameter).

Pore volumes of the different solids are listed in Table 1.

Acidity. All materials exhibited similar TPD profiles, with varying densities of acid sites (Table 1). MCM-41, KIT-6 and LiChrospher features around $0.1 \mathrm{mmol} / \mathrm{g}$ of strong acid sites, MCM-48 and HY-30 based catalyst around $0.2 \mathrm{mmol} / \mathrm{g}$ and $\mathrm{HY}-15$ based catalysts around $0.3 \mathrm{mmol} / \mathrm{g}$. The fact that similar desorption profiles are obtained is consistent with the high basic strength of $\mathrm{NH}_{3}\left(\mathrm{p} K_{\mathrm{b}}=4.75\right)$. Differences in acid strength can be therefore hardly seen. The method is however widely accepted to dose the total number of acid sites at the surface of solids due to its simplicity and to the good precision of the data recorded. In order to determine the nature of the acid sites, and to tentatively evidence differences in acid 

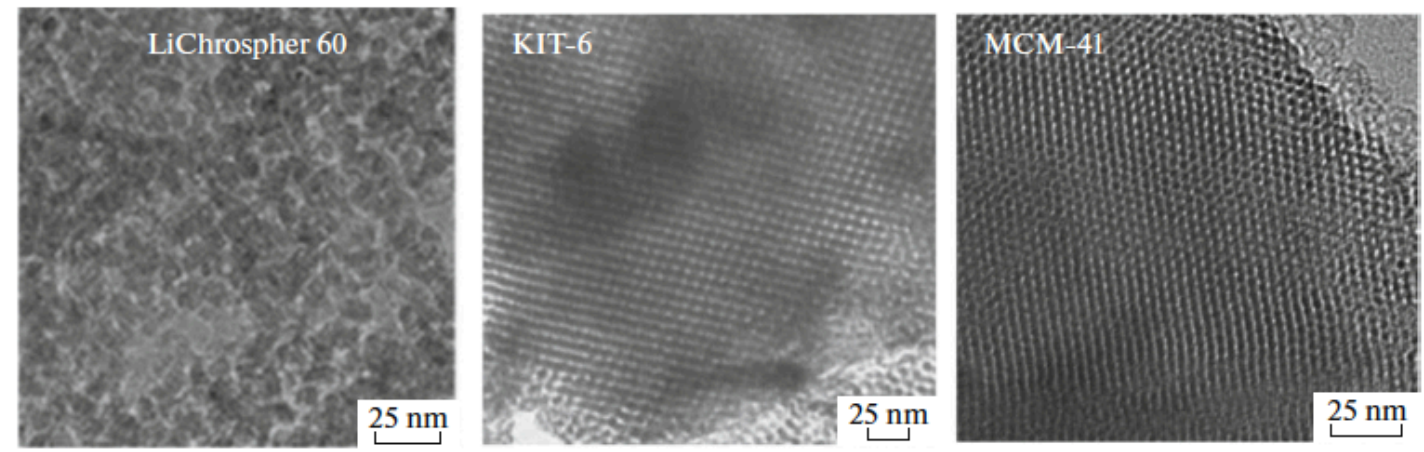

Fig. 4. TEM images of mesoporous materials.
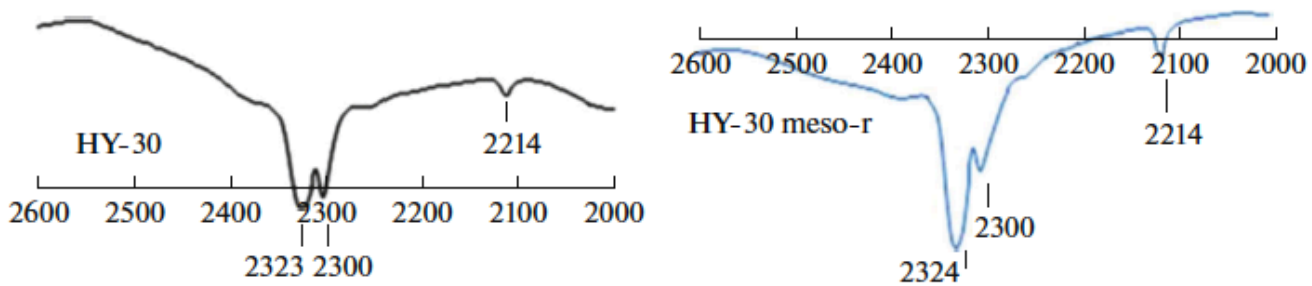

Wavenumber, $\mathrm{cm}^{-1}$

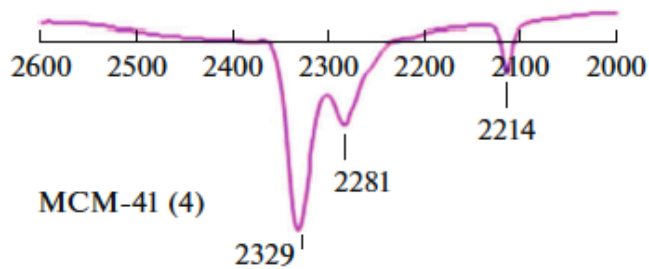

Wavenumber, $\mathrm{cm}^{-1}$

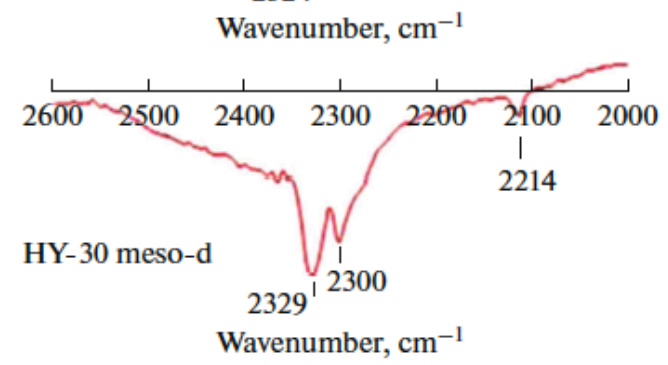

Fig. 5. Infrared spectra in the region of $\mathrm{CN}$ and $\mathrm{CD}$ vibrations for perdeuterated acetonitrile adsorbed on various catalysts after desorption at $50^{\circ} \mathrm{C}$.

strengths, we used IR spectroscopy of adsorbed perdeuterated acetonitrile. Acetonitrile is a weak base $\left(\mathrm{p} K_{\mathrm{b}}=-11\right)$, it doses only the strongest acid sites and allows to discriminate between Lewis and Brönsted sites [57-61]. After dosing 1.5 torr of acetonitrile at room temperature and desorbing the sample at $50^{\circ} \mathrm{C}$ for $15 \mathrm{~min}$, characteristic signals for acetonitrile adsorbed on Lewis sites $\left(2323-2329 \mathrm{~cm}^{-1}\right)$ and on Brönsted sites $\left(2280-2300 \mathrm{~cm}^{-1}\right)$ were detected (Fig. 5). (The signal at $2115 \mathrm{~cm}^{-1}$ corresponds to the symmetric C-D stretching mode of chemisorbed acetonitrile).

Though the acidity of the surface of the different materials was qualitatively similar, with however larger proportions of Lewis sites on the modified zeolites and on the aluminated mesoporous catalysts than on the starting HY-30 zeolite (Fig. 5), it can be noted that the position of the maximum of the peak associated to
Brönsted sites is slightly shifted towards lower wavenumbers in the case of mesoporous materials, suggesting a lower strength of their Brönsted sites (Table 2). Among purely mesoporous materials, MCM-48 aluminated by the aluminium alkoxide route features the highest strength of Brönsted sites and the highest number of strong acid sites (Table 1).

Catalytic activity. The activity of the catalysts for the conversion of $n$-hexadecane was evaluated under a total pressure of $20 \mathrm{~atm}$. with a molar $\mathrm{H}_{2} /$ hydrocarbon ratio of 4 in the temperature range $220-320^{\circ} \mathrm{C}$. Activity versus temperature curves are shown in Fig. 6. Arrhenius plots drawn for conversion levels lower than $30 \%$ allowed to calculate apparent activation energies in the range $120-140 \mathrm{~kJ} / \mathrm{mol}$ for all catalysts. Such values are characteristic for a bifunctional mechanism of alkane hydroconversion free from mass transport constraints [62]. 
Table 2. Position of the bands characteristic of Brönsted and Lewis acidity determined by IR of adsorbed acetonitrile

\begin{tabular}{c|l|c|c}
\hline Sample no. & \multicolumn{1}{|c|}{ Catalyst } & Band position Lewis, $\mathrm{cm}^{-1}$ & Band position Brönsted, $\mathrm{cm}^{-1}$ \\
\hline 3 & HY-30 & 2323 & 2300 \\
5 & HY-30 meso-d & 2329 & 2300 \\
6 & HY-30 meso-r & 2324 & 2300 \\
7 & MCM-41 & 2329 & 2281 \\
$8^{1}$ & MCM-48 & 2323 & 2290 \\
\hline
\end{tabular}

${ }^{1}$ From ref [31].

As reported previously $[28,31]$, under the experimental conditions used, no loss of activity nor selectivity was observed under long lasting and duplicate runs. Used catalysts featured a broad distribution of metal particles, with large particles $(>15 \mathrm{~nm})$ coexisting with a high population of small $(<3 \mathrm{~nm}, 50 \%$ of the particles detected) metal clusters. In terms of selectivity all catalysts demonstrated the behavior of ideal bifunctional catalysts $[63,64]$. The primary products formed were monobranched isomers. Increasing the conversion led to the production of multibranched isomers and ultimately cracking products formed above $\mathrm{ca} 40 \%$ total conversion (Fig. 7).

In terms of activity however large differences were revealed (Fig. 5). The catalysts with the highest strength of acidity, zeolite-based catalysts and MCM-48, demonstrated a higher activity than the other purely mesoporous catalysts with a temperature $40^{\circ} \mathrm{C}$ lower. Such a situation results from a difference in acid strength of the various solids, as evidenced by IR spectroscopy of adsorbed acetonitrile. Interestingly, for the zeolite-based catalysts and MCM-48, a unique linear relationship (Fig. 8) can be established between the reaction rate of $n$-hexadecane transformation at $230^{\circ} \mathrm{C}$ and the amount of strong acid sites measured by ammonia TPD. This unique correlation indicates that the acid sites present on these catalysts are of the same nature and strength as those present in the starting zeolite and are not modified by the alkaline treatments performed using or not surfactants.

Another difference concerning the maximum yields of isomer products was also clearly evidenced (Fig. 7 and Table 1). All materials (except the parent zeolites HY-30 and HY-15) demonstrated high selectivities in isomerization, with maximum isomer yields reached at very high total conversion $(80-90 \%)$ but with however definite differences between the catalysts. While this maximum was at $30 \%$ for HY- 15 at $c a$ $50 \%$ for HY-30 and $55-58 \%$ for the modified zeolites, it increased to $70 \%$ for the purely mesoporous catalysts. This isomer yield gain is consistent with a faster desorption of the primary products of the reaction favored by the increase of the mesoporosity of the catalysts as previously reported [28-32]. Our data allows however a further analysis of the phenomenon. They clearly suggest that the mesopore architecture (homo- geneity of sizes or interconnectivity) of the catalysts has little, if any, influence on selectivity, more precisely on the maximum isomer yields. For instance, despite a totally different mesoporous network, HY-30 meso-d and HY-30 meso-r (multimodal and broad distribution of mesopores sizes for HY-30 meso-d and monomodal with a very narrow mesopore size distribution for HY-30 meso-r) lead to equivalent amounts of isomers. Similarly, the isomer yields obtained with KIT-6, MCM-48 and LiChrospher (3 D network of mesopores) and MCM-41 (1 D network of mesopores) are identical. The key parameter governing selectivity in the hydroisomerization of $n$-hexadecane under the conditions of our study is definitely the mesopore volume of the catalysts, regardless of the architecture of the porous network, as shown in Fig. 9.

Relationship between mass transport and selectivity. In related works from our group, the mass transport properties of most porous supports used in the present study have been determined experimentally. It is therefore appealing to correlate the diffusion data with the catalysis results.

The effective diffusion coefficients for $\mathrm{n}$-hexane at room temperature in HY-15, HY- 15 meso-r and MCM-41 have been measured using PFG NMR spectroscopy $[65,66]$.

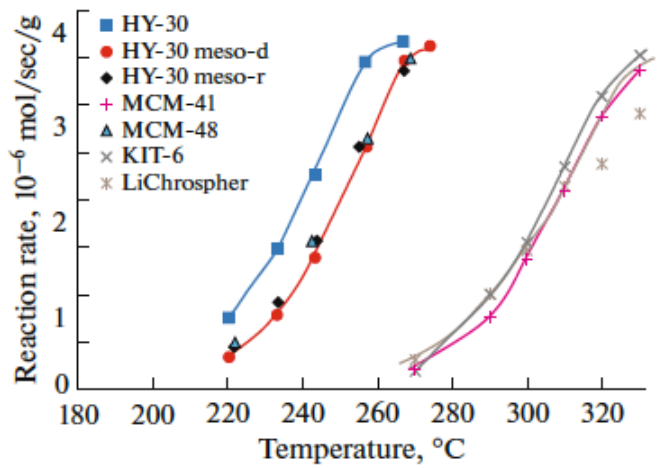

Fig. 6. Reaction rate of $n$-hexadecane conversion as a function of reaction temperature. 

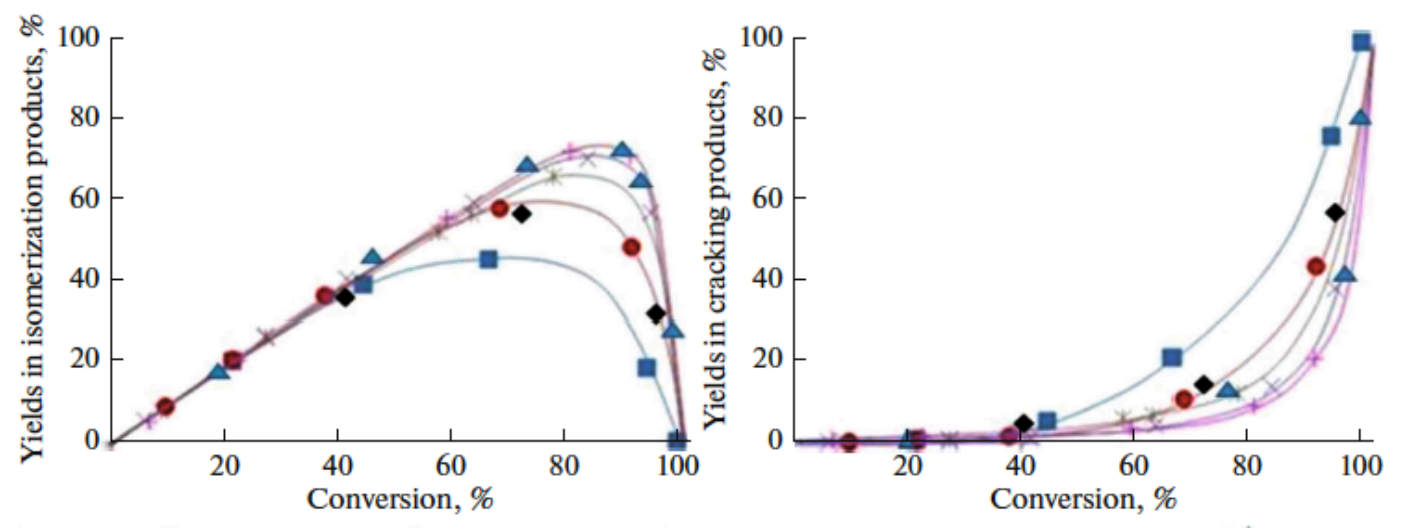

HY-30 HY-30 meso-d

41(4) $\times$ KIT-6 $\times$ LiChrospher $\triangle$ MCM-48

Fig. 7. Yields in isomerization and cracked products as a function of total $n$-hexadecane conversion.

On the other hand mass transport properties of MCM-41, LiChrospher, KIT-6 and MCM-48 have been determined from chromatographic measurements performed using dibutylphatalate as solute [67]. Data were obtained by employing the Van Deemter equation $(\mathrm{H}=\mathrm{A}+\mathrm{B} / \mathrm{u}+\mathrm{Cu})$, which correlates the plate height $(\mathrm{H}, \mathrm{mm})$ of a chromatography column with the linear velocity $(\mathrm{u}$, in $\mathrm{cm} / \mathrm{min}$, proportional to the flow rate $\mathrm{F}$, in $\mathrm{mL} / \mathrm{min}$ ) of a solute. In this equation, the term A represents the mass transfer in the macroporous network and is independent of flow rate, the B term is the lateral diffusion of the solute in the liquid (mainly dependent of the solute) and the $\mathrm{C}$ term represents the mass transfer in the mesoporous network of the sorbent particles [68, 69].

Galarneau et al. [70] showed that the chromatographic and the NMR data are correlated by the equation:

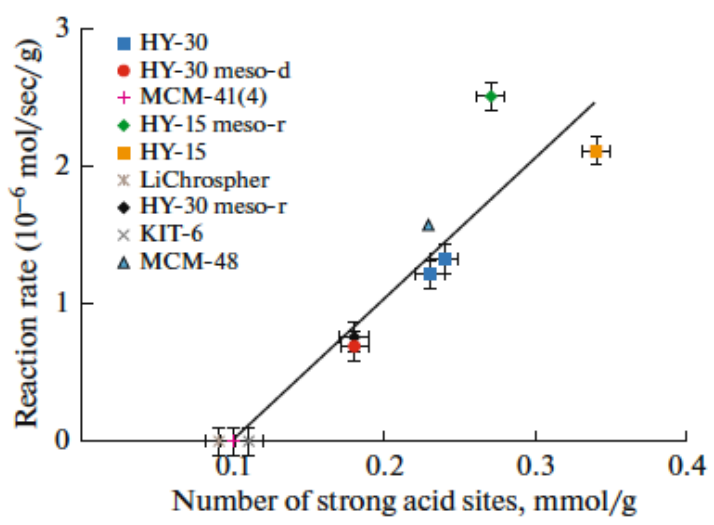

Fig. 8. Correlation between the rate of $n$-hexadecane transformation at $230^{\circ} \mathrm{C}$ and the number of strong acid sites measured by ammonia TPD.

$$
D_{\text {eff }}=\left(C_{m s} / C\right) d_{p}^{2}=A(1 / C)=B(t / m)(D / \sigma),
$$

where $C_{\mathrm{ms}}$ is the mass transfer flow, $D$ the mesopore diameter, $d_{\mathrm{p}}$ the particle size, $\sigma$ the molecule diameter, $m$ the pore geometrical factor $(m=2$ for a cylindrical pore, $m=3$ for a spherical pore) and $t$ the connecting factor ( $t=1$ for non connected pores, $t=1.45$ for connected pores).

Diffusion coefficients for $\mathrm{n}$-hexane and the resulting molecular diffusion rates are listed in Table 3 . The impact of the presence of mesopores in zeolite crystals and of the pore architecture-size and dimensionality-of mesoporous materials is distinctly highlighted.

In Fig. 10 we have plotted the maximum yields of isomer products formed during the hydroconversion of $n$-hexadecane versus the effective diffusion coefficients (left) and molecular diffusion rates (right) for typical porous supports used in the present study. Both

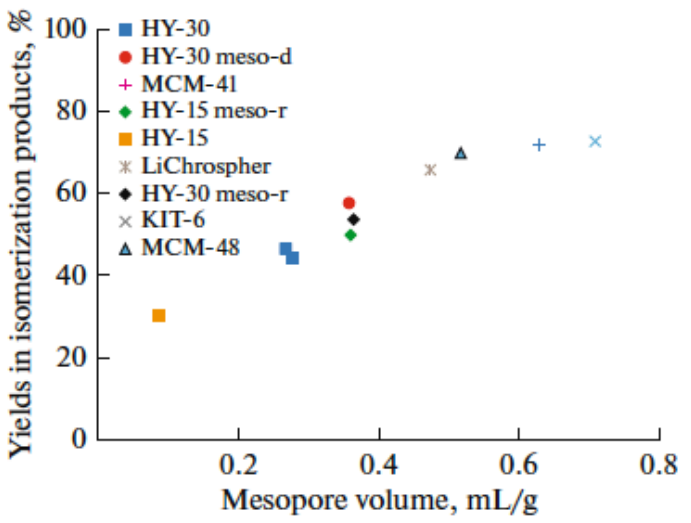

Fig. 9. Maximum isomer yields in the hydroconversion of $n$-hexadecane as a function of the mesopore volume of the catalysts. 
representations emphasize a steep increase in isomer yields upon generation of an additional mesoporous network of pores in zeolite crystals and a constant value of the isomer yield over the mesoporous catalysts, regardless of the geometry of their porous network and despite a wide variation of the transport kinetics.

Several semi-empirical models have been proposed to correlate catalytic performance and mass transfer in porous systems. Models integrating pore characteristics such as pore size, shape, tortuosity or connectivity $[1,6,10,71-73]$ show that diffusion rates increase continuously with pore diameter. Recently the group of Tallarek [74] has proposed an equation to express the diffusive hindrance factor $(\mathrm{H})$ which quantifies the degree to which diffusion through a mesoporous material $\left(D_{\text {eff }}\right)$ is hindered compared with diffusion in the bulk liquid $\left(D_{\mathrm{m}}\right)$ as a function of $\lambda$, the ratio between the solute size and the pore size $(H(\lambda)=$ $\left.D_{\text {eff }} / D_{\mathrm{m}}\right)$. This equation allows to establish quantitative morphology/transport relationships in separation processes and shows that, for a solute confined in mesopores, diffusion rate sharply increases with mesopore size up to a value corresponding to $\mathrm{ca} 10$ times the size of the solute. Above this threshold, diffusion rate is a single linear function of mesopore volume, but at the expense of loading capacity.

Since reactivity results from the interaction of the moving molecule with the active sites, catalytic performance will require maximum interaction with the surface, which is achieved in very small pores generating high surface area. These opposite trends imply that a compromise between mass transfer and reactivity has to be found in designing optimal catalysts. Such a compromise has been proposed to correspond to materials featuring pore diameters equivalent to 5-
Table 3. Effective diffusion coefficients $\left(D_{\text {eff }}\right)$ and molecular diffusion rates $(r)$ for $\mathrm{n}$-hexane at room temperature on porous supports

\begin{tabular}{l|c|c}
\hline \multicolumn{1}{c|}{ Material } & $D_{\text {eff }}, 10^{-10} \mathrm{~m}^{2} / \mathrm{s}$ & $r, \mu \mathrm{m} / \mathrm{s}$ \\
\hline HY-15 & $2.2^{1}$ & 0.36 \\
HY-15 meso-r & $14^{1}$ & 0.92 \\
MCM-41 & $120^{1}$ & 2.68 \\
MCM-48 & $150^{2}$ & 3.0 \\
LiChrospher & $200^{2}$ & 3.46 \\
KIT-6 & $300^{2}$ & 4.24 \\
\hline
\end{tabular}

${ }^{1}$ Measured by PFG NMR, ${ }^{2}$ calculated using Eq. (1).

7 times the size of the reactant molecules [70]. Interestingly this value is close to that proposed by Tallarek [74] for separation applications.

It is remarkable to note that a ratio of 7 would correspond to a system of cylindrical pores in which the same amount of molecules stand in the adsorbed state and in the mobile phase inside the pore.

If we refer to the case of the hydroconversion of $n$ hexadecane, and taking a value of $0.53 \mathrm{~nm}$ for the kinetic diameter of mono-branched alkanes [75], the above hypothesis would predict an optimun pore size of $c a 3.5 \mathrm{~nm}$, fully in line with our observations.

\section{CONCLUSION}

Hydroconversion of $n$-hexadecane over a series of model bifunctional catalysts featuring acidic components with well-defined distinct porous architectures allows us to bring new insights into the role of porosity on catalytic performance. Creation, or increasing the

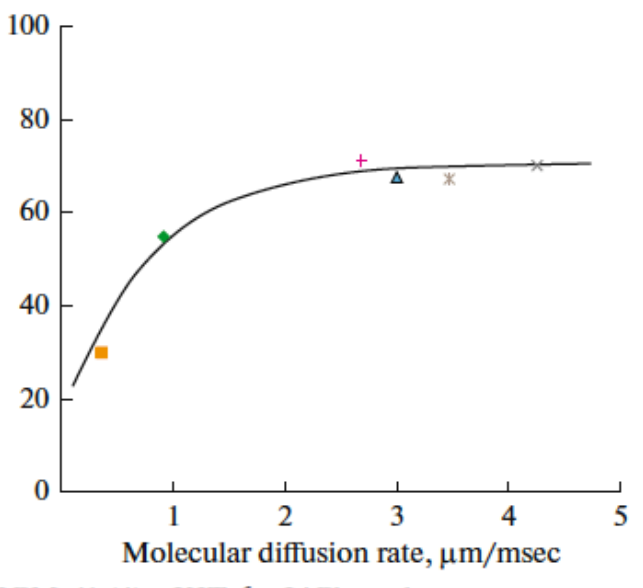

Fig. 10. Correlation between the maximum $n$-hexadecane isomer yield and the diffusion characteristics of typical porous supports used in the study. 
volume of mespores in zeolitic materials leads, as expected, to a significant increase of the isomerization selectivity by favoring the rapid desorption of the primary products. For a given mesopore volume, the structuration or the ordering of the mesoporous network does not bring additional benefit in terms of catalyst efficiency. In the case of purely mesoporous materials, the isomer selectivity is also a function of the mesopore volume, and, here again, the pore size, shape and connectivity do not influence catalytic outcome while, at the same time, these factors have a strong impact on diffusion kinetics. Since catalytic processes require both fast mass transport-favored in larger pores-and interaction with a large active surface-favored in small pores-it is suggested that an optimum pore size, set at 5-7 times the size of the reactant molecules, would result in optimal catalytic performance. Such an optimal pore diameter would be at $c a 3.5 \mathrm{~nm}$ for the hydroconversion of $n$-hexadecane and corresponds to the pore sizes of the MCM-41 and MCM-48 type materials. Larger pore sizes, up to $7 \mathrm{~nm}$ for KIT- 6 for instance, allow faster diffusion kinetics but do not bring additional selectivity benefit.

Our data show moreover that activity is a linear function of the number of strong acid sites. The use of different methods for the alumination of mesoporous catalysts, by direct synthesis for MCM-41, by alumination using alkoxide in organic medium for MCM48 or by deposition of alumina in aqueous medium for KIT-6 and LiChrospher reveals dramatic differences in the strength of the acid sites generated. The alkoxide route produces acid sites with a strength comparable to that of zeolites.

In spite of its simplicity, the concept of optimal pore size should prove very useful for the selection of optimal catalysts in many catalytic processes.

\section{ACKNOWLEDGMENTS}

The authors thank Total S.A. for fruitful discussions and financial support. L.V. thanks ANRT and Total for a grant. The authors wish to acknowledge the support from the Chemistry Plateform of Campus in Montpellier (Plateform MEA University Montpellier), on which TEM and EDS experiments have been performed.

\section{REFERENCES}

1. W. Vermeiren, and J. P. Gilson, Top. Catal. 52, 1131 (2009).

2. E. Ruckenstein and M.C. Tsai, AIChE J. 27, 697 (1981).

3. E. Benazzi, L. Leite, N. Marchal-George, et al., J. Catal. 217, 376 (2003).

4. K. Sato, Y. Nishimura, H. Shimada, Catal. Lett. 60, 83 (1999).

5. K. Sato, Y. Nishimura, K. Honna, et al., J. Catal. 200, 288 (2001).
6. H. Toulhoat, P. Raybaud, E. Benazzi, J. Catal. 221, 500 (2004).

7. M. O. Kazakova, K. A. Nadeina, I. G. Danilova, et al., Catal. Today 305, 117 (2018).

8. E. G. Derouane, J. M. André, and A. A. Lucas, J. Catal. 110, 58 (1988).

9. I. Derijcke, J. P. Vigneron, Ph. Lambin, A. A. Lucas, and E. G. Derouane, J. Chem. Phys. 94, 4620 (1991).

10. E. G. Derouane, J. Mol. Catal., A 134, 29 (1998).

11. H. Deldari, Appl. Catal., A 293, 1 (2005).

12. V. M. Akhemedov, and S. H. Al-Khowaiter, Catal. Rev. 49, 33 (2007).

13. C. Bouchy, G. Hastoy, E. Guillon, and J. A. Martens, Oil Gas Sci. Technol. 64, 91 (2009).

14. M. Guisnet, Catal. Today 218, 123 (2013).

15. P. Maki-Arvela, T. A. Kaka-khel, M. Azkaar, et al., Catalysts 8, 534 (2018).

16. W. Wang, C.-J. Liu, and W. Wu, Catal. Sci. Technol. 9, 4162 (2019).

17. K.-C. Park and S.-K. Ihm, Appl. Catal., A 203, 201 (2000).

18. A. Soualah, J. L. Lembreton, L. Pinard, et al., Appl. Catal., A 336, 23 (2008).

19. F. M. Mota, C. Bouchy, E. Guillon, et al., J. Catal. 301, 20 (2013).

20. W. Souverijns, J. A. Martens, G. F. Froment and P. A. Jacobs, J. Catal. 174, 177 (1988).

21. J. Weitkamp, ChemCatChem. 4, 292 (2012).

22. J. W. Thybaut, I. R. Choudhury, J. F. Denayer, et al.,Top. Catal. 52, 1251 (2009.

23. A. Astafan, Y. Pouilloux, J. Patarin, et al., New J. Chem. 40, 4335 (2016).

24. Y. Chen, S. Liu, H. K. Zhang, et al., J. Catal. 361, 177 (2018).

25. P. Niu, H. Xi, J. Ren, et al., Catal. Sci. Technol. 7, 5055 (2017).

26. Y. Bi, G. Xia, W. Huang, and H. Nie, RSC Adv. 5, 99201 (2015).

27. X. Wu, M. Qiu, X. Chen, et al., New J. Chem. 42, 111 (2018).

28. K. P. de Jong, J. Zecevic, H. Friedrich, et al., Angew. Chem., Int. Ed. Engl. 49, 10074 (2010).

29. J. A. Martens, D. Verboekend, K. Thomas, et al., Catal. Today 218-219, 135 (2013).

30. Y. Chen, C. Li, X. Chen, et al., Microporous Mesoporous Mater. 268, 216 (2018).

31. R. Kenmogne, A. Finiels, C. Cammarano, et al., J. Catal. 329, 348 (2015).

32. H. Song, Z. Liu, W. Xing, et al., Appl. Petrochem. Res. 4, 401 (2014).

33. Y. Goto, Y. Fukushima, P. Ratu, et al., J. Porous Mater. 9, 43 (2002).

34. I. I. Ivanova, A. S. Kuznetsov, V. V. Yuschenko, and E.E. Knyazeva, Pure Appl. Chem. 76, 1647 (2004).

35. S. Inagaki, M. Ogura, T. Inami, et al., Microporous Mesoporous Mater. 74, 163 (2004).

36. V. V. Ordomsky, V. Y. Murzin, Yu. V. Monakhova, et al., Microporous Mesoporous Mater. 105, 101(2007). 
37. J. Y. Ying and J. Garcia-Martınez, US Patent No. 7,589,041 (2009).

38. J. Garcia-Martinez, M. Johnson, J. Valla, et al., Catal. Sci. Technol. 2, 987 (2012).

39. M. O. Kazakov, K A. Nadeina, I. G. Danilova, et al., Catal. Today, 305, 117 (2018).

40. R. Chal, T. Cacciaguerra, S. van Donk, and C. Gerardin, Chem. Commun. 46, 7840 (2010).

41. R. Chal, C. Gerardin, M. Bulut, and S. van Donk, ChemCatChem. 3, 67 (2011).

42. F. Kleitz, S. H. Choi, and R. Ryoo, Chem. Comm. 17, 2136 (2003).

43. N. Calin, A. Galarneau, T. Cacciaguerra, et al., C. R. Chim. 13, 199 (2010).

44. D. Desplantier-Giscard, A. Galarneau, F. Di Renzo and F. Fajula, Stud. Surf. Sci. Catal. 135, 1105 (2001).

45. A. Galarneau, M. Nader, F. Guenneau, et al., J. Phys. Chem. B, 111, 8268 (2007)

46. A. Galarneau, M. F. Driole, C. Petitto, et al., Microporous Mesoporous Mater. 83, 172 (2005).

47. P. Iengo, M. Di Serio, A. Sorrentino, et al., Appl. Catal., A 167, 85 (1998).

48. Z. Luan, M. Hartmann, D. Zhao, et al., Chem. Mater 11, 1621 (1999).

49. R. D. Andrei, M. I. Popa, F. Fajula, and V. Hulea, J. Catal. 323, 76 (2015).

50. A. Galarneau, D. Desplantier, R. Dutartre, and F. Di Renzo, Microporous Mesoporous Mater. 27, 297 (1999).

51. A. Galarneau, F. Villemot, J. Rodriguez, et al., Langmuir 30, 13266 (2014).

52. P. I. Ravikovitc and A.V. Neimark, Langmuir 18, 9830 (2002).

53. D. Mehlhorn, J. Rodriguez, T. Cacciaguerra, et al., Langmuir, 34, 11414 (2018).

54. I. I. Ivanova and E. E. Knyazeva, Chem. Soc. Rev. 42, 3671 (2013).

55. D. Verboekend, M. Milina, S. Mitchell, and J. PerezRamirez, J. Cryst. Growth Des. 13, 5025 (2013).
56. D. Verboekend, N. Nuttens, R. Locus, et al., Chem. Soc. Rev. 45, 3331 (2016).

57. C. Angell and M. Howell, J. Phys. Chem. 73, 2551 (1969).

58. G. Eaton, A. Pena-Nunez, and M. Symons, J. Chem. Soc., Faraday Trans. 84, 2181 (1988).

59. A. S. Medin, V. Yu. Borovkov, V. B. Kazansky, et al., Zeolites 10, 668 (1990).

60. A. G. Pelmenschikov, R. A. van Santen, J. Janchen, and E. Meijerl, J. Phys. Chem. 97, 11071 (1993).

61. S. Jolly, J. Saussey, and J. C. Lavalley, J. Mol. Catal. 86, 401 (1994).

62. C. Travers, N. Essayem, M. Delage, and S. Quelen, Catal. Today 65, 355 (2001).

63. H. I. Coonradt and W. E. Garwood, Ind. Eng. Chem. Process Des. Dev. 3, 38(1964).

64. J. Weitkamp, ACS Symposium Series, vol. 20: Hydrocracking and Hydrotreating, Ed. by J. W. Ward (American Chemical Society, Washington, DC, 1975), p. 1.

65. Z. Adem. F. Guenneau, M. A. Springuel-Huet. et al., J. Phys. Chem. C 116, 13749 (2012).

66. A. Galarneau, F. Guenneau, A. Gedeon, et al., J. Phys. Chem. C 120, 1562 (2016).

67. A. Galarneau, J. Iapichella, D. Brunel, et al., J. Sep. Sci. 29, 844 (2006).

68. J. J. van Deemter, F. J. Zuiderweg, and A. Klinkenberg, Chem. Eng. Sci. 5, 271 (1956).

69. V. Wernert, R. Bouchet, and R. Denoyel, Anal. Chem. 82, 2668 (2010).

70. A. Galarneau, A. Sachse, B. Said, et al., C. R. Chim. 19, 231 (2016).

71. E. M. Renkin, J. Gen. Physiol. 38, 225 (1954).

72. V. R. Choudhary and L. K. Doraiswamy, Ind. Eng. Chem. Prod. Res. Dev. 10, 218 (1971).

73. E. N. Fuller, P. D. Schettler, and J. C. Giddings, Ind. Eng. Chem. 58, 18 (1966).

74. S. J. Reich, A. Svidrytski, D. Hlushkou, et al., Ind. Eng. Chem. Res. 57, 3031 (2018).

75. D. Peralta, G. Chaplais, A. Simon-Masseron, et al., Ind. Eng. Chem. Res. 51, 4692 (2012). 